\title{
Materiais gráficos para atendimento educacional especializado de pessoas com baixa visão: análise gráfica e requisitos
}

\author{
Graphic materials for specialized educational assistance for low vision: \\ graphic analysis and requirements
}

Karina de Abreu Antoniolli, Juliana Bueno

design centrado no humano, eficiência visual, análise gráfica, baixa visão

O projeto "Tela Multitoque para Auxílio ao Atendimento Especializado de Pessoas com Baixa Visão: uma experiência centrada no humano" procura adequar um modelo de atendimento baseado em materiais didáticos artesanais (pranchas) para contexto digital, apoiando-se no processo de Design Centrado no Humano dividido em 3 etapas (IDEO, 2015). Detalha-se neste artigo o procedimento de catalogação e análise gráfica das pranchas, realizado na primeira etapa, em que se empregou as quatro seções da Escala de Eficiência Visual proposta por Barraga (1970) e fundamentos de design pela definição de vários autores. A partir das análises gráficas, são propostos requisitos para produção de materiais e exercícios desse tipo, considerando também os objetivos de cada seção da Escala e os princípios de Design elencados. Os dados aqui apresentados e outros coletados durante a pesquisa serão a base para o desenvolvimento das duas próximas etapas do projeto.

human-centered design, visual efficiency, graphic analysis, low vision

The project "Multitouch Screen to Aid Specialized Assistance for People with Low Vision: a humancentered experience" seeks to adapt an assistance model based on handmade didactic materials (boards) for the digital context, with a Human-Centered Design process divided into 3 stages (IDEO, 2015). The procedure of cataloging and graphic analysis of the boards, carried out in the first stage, is detailed in this article, in which the Visual Efficiency Scale proposed by Barraga (1970) and design fundamentals by the definition of several authors were used. Based on the graphic analysis, requirements for the production of materials and exercises of this type are proposed, also considering the objectives of each section of the Scale and the design principles listed. The data presented here and other collected during the research will be the basis for the development of the next two stages of the project.

\section{Introdução}

A baixa visão é um tipo de deficiência visual e, como define a organização Web Accessibility in Mind (WebAIM, 2013), pode se manifestar em qualquer pessoa, de qualquer idade, sendo considerada mais comum em pessoas idosas. No Brasil, a região Sul é a que possui o maior índice de deficiência visual, sendo 5,9\% da população (Instituto Brasileiro de Geografia e Estatística [IBGE], 2015).

Anais do $10^{\circ} \mathrm{CIDI}$ e $10^{\circ} \mathrm{CONGIC}$

Kelli C.A.S. Smythe, Rafael de Castro Andrade (orgs.)

Sociedade Brasileira de Design da Informação - SBDI

Curitiba | Brasil | 2021
Proceedings of the $10^{\text {th }} \mathrm{CIDI}$ and $10^{\text {th }}$ CONGIC

Kelli C.A.S. Smythe, Rafael de Castro Andrade (orgs.)

Sociedade Brasileira de Design da Informação - SBDI Curitiba | Brazil | 2021 
No geral, a maioria das pessoas possui a deficiência visual em decorrência de doença ou acidente, enquanto a minoria nasce com algum tipo de deficiência visual.

Para pessoas com diagnóstico de baixa visão, é de suma importância o trabalho contínuo de eficiência visual, um trabalho educacional, que tem o objetivo de estimular a visão residual. Natalie Barraga (1970), precursora de estudos na área, desenvolveu a Escala de Eficiência Visual, com diversos exercícios para estimular corretamente a visão de cada pessoa com baixa visão.

Desde então, este material, assim como as funções visuais de Barraga (1985), tem subsidiado o modelo de atendimento dos chamados Centros de Atendimento Educacional Especializado (CAEEs). Nesse contexto, os exercícios de estimulação visual (pranchas) são em suma desenvolvidos manualmente pelos profissionais dos CAEEs, utilizando cartolinas e sucatas.

Por mais que estas pranchas se configurem como artefatos gráficos e didáticos, estas foram feitas por pessoas que não são designers. Uma pesquisa preliminar feita por meio de revisão bibliográfica assistemática demonstrou não haver estudos na área de Design da Informação de acordo com o escopo deste estudo. Neste sentido e com o intuito de transpor este modelo de atendimento com pranchas para o meio digital e aprimorar estes materiais por meio do Design da Informação, em parceira com o CAEE Natalie Barraga de Curitiba - PR, o projeto de pesquisa "Tela Multitoque para Auxílio ao Atendimento Especializado de Pessoas com Baixa Visão: uma experiência centrada no humano" objetiva produzir materiais interativos, interligando os pressupostos teóricos que pautam as pranchas de estimulação visual, Design de Interação e fundamentos de Design.

Como parte fundamental para a pesquisa, este artigo, resultado de uma iniciação científica, apresenta um recorte da primeira etapa do projeto, com foco no registro fotográfico, catalogação e análise gráfica preliminar destas pranchas de pareamento e justaposição baseada em fundamentos de design e nas seções da Escala de Eficiência Visual de Barraga (1970), assim como um levantamento preliminar de requisitos.

\section{Fundamentação teórica}

Apresenta-se aqui, referências relevantes à análise de materiais. Entretanto, realizou-se uma extensa revisão de literatura nos temas do projeto.

No cenário da abordagem educacional da deficiência visual, a Escala de Eficiência Visual (Barraga, 1970), atualizada por Fuente e Martín (2005), possui exercícios em preto e branco, sem testes manipulativos, divididos em 4 grupos de habilidade visuais. São no total 48 itens, sendo tarefas de associação e discriminação visual (Fuente \& Martín, 2005):

- Seção 1: discriminação de formas geométricas, contorno de objetos, intensidade claroescuro, tamanho e posição;

- Seção 2: discriminação de tamanho, detalhes de objetos e figuras abstratas, posição no espaço, constância de forma e detalhes de padrões e objetos; 
- Seção 3: encaixe visual, perspectiva espacial, discriminação de detalhes em figuras abstratas e objetos;

- Seção 4: discriminação de tamanho, posição, sequência e relações entre letras, palavras, símbolos e grupos de símbolos.

Desta maneira, é possível avaliar os resultados entre baixa eficiência e eficiência satisfatória com auxílio da folha de resposta (Barraga, 1970), e estimular corretamente a capacidade visual de cada indivíduo.

No CAEE Natalie Barraga, as pranchas de pareamento e justaposição produzidas são baseadas também nas 3 funções visuais (Figura 1), definidas por Barraga (1985).

Figura 1: Funções visuais. Fonte: Barraga (1985).
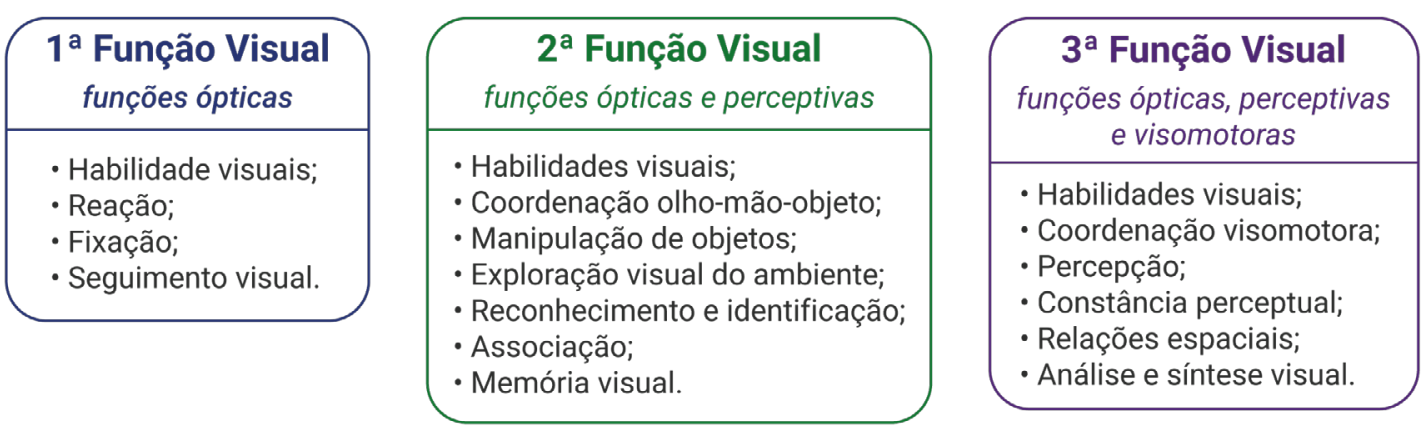

Entende-se que esses exercícios são compostos de formas, linhas e outros elementos básicos do Design, embora não seja proposital. Assim, destaca-se a importância da linguagem visual, que possui princípios básicos como outras.

Leborg (2015) divide os conceitos de linguagem visual em duas classificações mais amplas, abstrato e concreto, com estruturas e objetos, e desenvolvidas como relações e/ou atividades.

Sem classificações tão abrangentes, Lupton e Phillips (2013) entendem alguns princípios iguais, como ponto, linha, plano, textura e cor. Porém, também consideram outros como: enquadramento, figura-fundo, escala, ritmo e equilíbrio, hierarquia, camadas, modularidade, grid, padronagem, diagrama, transparência, tempo e movimento.

Gomes Filho (2004) relaciona alguns princípios colocados por Lupton e Phillips (2013) com conceitos da Gestalt, ligados à percepção visual e pregnância das formas. Nesse contexto, entende-se que uma imagem, ou produto, com pregnância alta incorpora conceitos como equilíbrio e harmonia, gerando clareza na visualização (Gomes Filho, 2004).

Assim, tendo os sete fundamentos básicos da Gestalt - segregação, semelhança, unidade, proximidade, continuidade, fechamento e figura-fundo - como base, Gomes Filho (2004) coloca um sistema de leitura visual da forma, entendendo-a, portanto, como ponto, linha, plano, volume e em diferentes configurações. Além disso, este define categorias conceituais, considerando princípios como harmonia, equilíbrio e contraste.

Alguns autores se propõem a abordar de maneira específica determinados conceitos, como é o caso de Farina (2006), que também cita a Gestalt e define que o elemento "cor" é 
impactante pela sua sensação estética, mas também como é utilizado, ao transmitir ideias, possuindo peso, equilíbrio e movimento. Já Lupton e Lipps (2018) destacam a importância de texturas, ao considerar que o design vai além do visual, ativando os 5 sentidos e permitindo que todos recebam a informação que está sendo passada.

Estas informações formam a base dos procedimentos apresentados em Metodologia.

\section{Metodologia}

A metodologia empregada no projeto é a do Design Centrado no Humano (IDEO (2015), com três etapas principais, sendo: Inspiração, Ideação e Implementação. Reforça-se que, a primeira etapa da pesquisa, Inspiração, da qual trata o artigo, contou com três procedimentos realizados a partir da pesquisa de campo no local e a revisão de literatura apresentada anteriormente. No artigo, apenas uma parte destes procedimentos é exposto, sendo o registro fotográfico com catalogação e análise preliminar de materiais utilizados nos atendimentos do CAEE Natalie Barraga.

Como citado acima, no local, os materiais foram fotografados e catalogados conforme a categorização da Escala de Eficiência Visual, e, ao todo, registrou-se pelo menos 400 pranchas de exercícios diferentes.

Estas possuem o objetivo de estimular a visão residual de discentes, variando entre pareamentos visuais, exercícios de justaposição, jogos e brinquedos criados pelas docentes e outros já existentes, placas com texturas, etc. Eles também são, em sua maioria, produzidos manualmente pelas docentes, com materiais reciclados e de fácil aquisição, como papelão, E.V.A. e tampas de garrafa. Além disso, seus formatos não possuem um padrão específico, variando entre $A 3, A 4$, retângulos e quadrados.

Nesse contexto, selecionou-se uma amostra de 40 pranchas, com conteúdos referentes às 4 seções de Barraga (1970), sendo 10 pranchas para cada uma, parte ilustrada na Figura 2. Considerando as pranchas como artefatos gráficos, realizou-se a análise com base em princípios de design de Lupton e Phillips (2013) - linha, textura, cor, figura fundo, margens, contorno e camada -, Gomes Filho (2004) - unidade, semelhança, proximidade e contraste - e Leborg (2015) - forma, rotação, movimento e repetição -, com uma tabela por autor. O uso de cada elemento de design nos exercícios foi mensurado entre 0 (nenhum uso) a 3 (muito uso), possibilitando uma síntese de elementos mais utilizadas em cada seção. 
Figura 2: Parte da amostra selecionada para análise. Fonte: autoras.

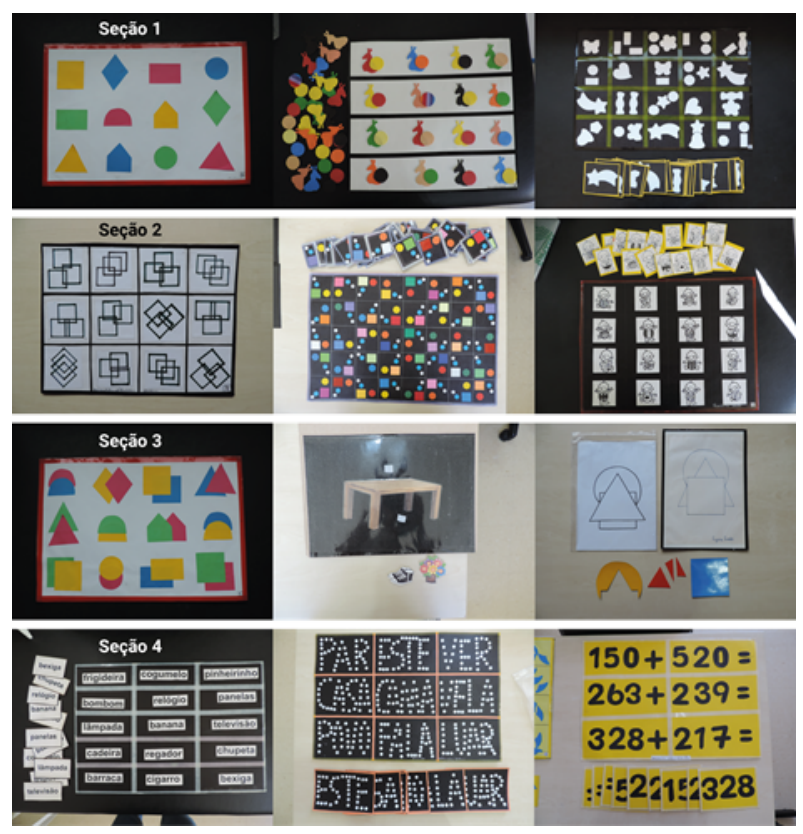

\section{Resultados}

A partir das análises, foi levantado um conjunto prévio de requisitos para produção de materiais didáticos e exercícios desta natureza para o público de baixa visão, considerando os objetivos de cada seção.

Assim, oriundos da análise da Seção 1 têm-se:

- Empregar cores com contraste para diferenciar formas geométricas em repetição;

- Separar formas diferentes, ou agrupar formas semelhantes, por meio de elementos delimitadores, criando blocos de informação;

- Utilizar contornos e linhas para a diferenciação de objetos;

- Criar uma unidade visual em cada material, ou unidades entre blocos de informação, utilizando elementos coerentes entre si.

Seção 2:

- Utilizar contornos para representar detalhes em objetos e figuras abstratas;

- Aplicar cores contrastantes para diferenciar formas em repetição nos exercícios e também distinguir detalhes em padrões;

- Definir blocos de informação por meio de margens e criação de uma unidade visual para o todo ou partes.

Seção 3:

- Aplicar cores contrastantes para diferenciar formas aplicadas em diferentes camadas; 
- Utilizar melhor contornos e linhas para denotar detalhes em objetos e figuras abstratas, como no exercício proposto nesta seção;

- Apresentar formas e contornos incompletos para exercícios de encaixe visual.

\section{Seção 4:}

- Aplicar o princípio de proximidade para a discriminação de sequências entre letras repetidas, formando palavras;

- Não utilizar rotações e camadas de forma a não comprometer a legibilidade;

- Utilizar cores para diferenciar grupos, palavras ou símbolos, criando unidades visuais.

Enfatiza-se que estes requisitos foram pensados apenas com base na análise dos materiais do CAEE Natalie Barraga, sendo produzidos por pessoas que não eram designers.

\section{Considerações finais}

Pessoas com baixa visão necessitam de materiais didáticos específicos para estimulação visual, estes materiais (pranchas) são confeccionados por docentes de CAEEs, O projeto "Tela Multitoque para Auxílio ao Atendimento Especializado de Pessoas com Baixa Visão: uma experiência centrada no humano" busca adaptar o modelo de atendimento baseado em pranchas artesanais para contexto digital. Tal projeto está dividido em 3 etapas.

Este artigo traz resultados provenientes da etapa 1 do projeto, que contou com 3 procedimentos metodológicos. Dentre os 3 , detalha-se o procedimento de catalogação e análise gráfica dos exercícios, levando em consideração a Escala de Eficiência Visual proposta por Barraga (1970) e fundamentos de Design pela definição de vários autores.

A partir das análises gráficas, foram propostos requisitos para produção de materiais e exercícios desse tipo, considerando os objetivos de cada seção da Escala Visual e os fundamentos de Design elencados. O Design da Informação pode auxiliar no aprimoramento da apresentação e função destes materiais, com alterações de leiaute, tipografia e uso de cores e elementos.

Os dados aqui apresentados e outros coletados durante a pesquisa serão a base para o desenvolvimento das duas próximas etapas de projeto.

\section{Referências}

Barraga, N. (1970). Visual Efficiency Scale. Louisville, KY: American Printing House for the Blind.

Barraga, N. (1985). Disminuidos visuales y aprendizaje (enfoque evolutivo). Madrid, ES: Organización Nacional de Ciegos de Espana.

Farina, M. (2006). Psicodinâmica das cores em comunicação. 5. ed. rev. e aum. São Paulo: Edgard Blucher. 
Fuente, B. E. de la, \& Martín, M. B. (2005). Escala de Eficiencia Visual de Natalie Barraga. III Congreso Virtual INTEREDVISUAL sobre La Autonomía Personal de Personas con Ceguera o Deficiencia Visual, Espanha.

Gomes Filho, J. (2004). Gestalt do Objeto. São Paulo: Escrituras Editora, 6a ed.

Instituto Brasileiro de Geografia e Estatística. (2015). Pesquisa nacional de saúde: 2013: ciclos de vida: Brasil e grandes regiões. IBGE, Coordenação de Trabalho e Rendimento. Rio de Janeiro: IBGE.

IDEO. (2015). The Field Guide to Human-Centered Design. 2. Ed. Disponível em https://www.designkit.org//resources/1

Leborg, C. (2015). Gramática visual. São Paulo: Gustavo Gilli.

Lupton, E., \& Phillips, J. C. (2013). Novos fundamentos do design. São Paulo: Cosac Naify.

Lupton, E., \& Lipps, A. (2018). The Senses: Design Beyond Vision. 1. ed. Hudson, NY: Princeton Architectural Press.

Web Accessibility in Mind. (2013). Visual Disabilities: Low Vision. Disponível em https://webaim.org/articles/visual//owvision

\section{Sobre as autoras}

Karina de Abreu Antoniolli, Graduanda, UFPR, Brasil <antoniolli.kari@gmail.com> Juliana Bueno, Doutora, UFPR, Brasil <julianabueno.ufpr@gmail.com> 